\title{
Participatory soundscape sensing
}

2 ABSTRACT: Soundscape research offers new ways to explore the acoustic environment and

3 potentially address challenges. A comprehensive understanding of soundscape characteristics

4 and quality requires efficient data collection and analysis methods. This paper describes

5 Participatory Soundscape Sensing (PSS), a worldwide soundscape investigation and

6 evaluation project. We describe the calibration method for sound pressure levels (SPL)

7 measured by mobile phone, analyze the PSS's data temporal-spatial distribution

8 characteristics, and discuss the impact of the participants' age and gender on the data quality.

9 Furthermore, we analyze the sound comfort level relationships with each class of land use,

10 sound sources, subjective evaluation, sound level, sound harmoniousness, gender, and age

11 using over a year of shared data. The results suggest that PSS has distinct advantages in

12 enhancing the amount and coverage of soundscape data. The PSS data distribution is closely

13 related to the temporal pattern of the human work-rest schedule, population density, and the

14 level of cyber-infrastructure. Adults (19-40 years old) are higher-quality data providers, and

15 women exhibit better performance with respect to data integrity than men. Increasing the

16 proportion of natural source sounds and reducing the proportion of human-made sources of

17 sound is expected to enhance the sound comfort level. A higher proportion of sound

18 harmoniousness leads to higher sound comfort, and the higher proportion of subjective

19 evaluation sound level does not lead to decreased sound comfort. We suggest that the

20 crowdsourcing data with participatory sensing will provide a new perspective in soundscape

21 investigation, evaluation, and planning.

22 KEYWORDS: Soundscape; participatory sensing; environmental noise; urban; citizen

23 science

\section{1. Introduction}

25 Soundscape can be defined as the acoustic environment perceived, experienced, and/or

26 understood by a person or people in a given context (ISO 12913-1, 2014), which places 
emphasis on the perception, evaluation, and experience of the listeners. The urban soundscape approach considers the acoustic environment as a "resource" (Brown, 2012) with the goal of improving urban sound quality via design and planning. The main topics of the urban soundscape include sound source identification (Jeon \& Hong, 2015), spatial-temporal variation (Hong \& Jeon, 2017; Liu et al., 2013), indicators selection (Aletta et al., 2016), sound evaluation (Yang \& Kang, 2005; Zhang et al., 2016), and soundscape design (Chung et al., 2016). Soundscape research methods, including pen and paper questionnaires, interviews, sound walks, and replaying of sound records in the lab, have been used to collect data, such as sound sources, sound pressure levels, location information, individual feelings, and demographic factors, among others (He \& Pang, 2016; Kang, 2014; Liu et al., 2014), and most of these factors have significant costs and time investment. Lab tests mean that volunteers cannot feel the real soundscape directly and, moreover, a long test can easily tire the participants. As a result, current research projects are primarily conducted at a small scale, such as in a park or green space, which leads to results that are difficult to apply on a large scale. Because soundscape design includes multi-party participation and discussion, reasonable soundscape design requires additional participants (He \& Pang, 2016). Participatory sensing (PS) is the process through which individuals and communities use the capabilities of mobile devices and cloud services to collect, analyze, and contribute sensory information (Estrin et al., 2010; Burke et al., 2006). Using the concept of PS, sound-recording and noise-monitoring mobile applications and online web survey software have been reported. Noteworthy is that some mobile phones' accuracy for measuring noise pollution has been tested (Aumond et al., 2017), but few of them may be appropriate for noise measurement (Kardous \& Shaw, 2014). The soundscape quality-related information, including such factors as sound pressure level (SPL), sound frequency, land use, or subjective evaluation, cannot be completely recorded (Becker et al., 2013; Cordeiro et al., 2013; Craig et al., 2017; Drosatos et al., 2014; Hedfors, 2013; Yelmi et al., 2016). Additionally, the quality and characteristics of these crowdsourced data lack detailed descriptions or discussion. 
In this paper, we propose Participatory Soundscape Sensing (PSS), which is an ongoing worldwide soundscape investigation and evaluation project that engages the public in participatory sensing. We describe the PSS tools and the calibration method of SPL as measured by mobile phones. We analyze the temporal-spatial distribution characteristics of the PSS data; discuss the impact of the participants' age and gender on the quality of data, including length of measurement time and soundscape records integrity; and analyze the sound comfort level relationships with each class of land use, sound sources, subjective evaluation sound level, sound harmoniousness, gender, and age.

\section{Methodology}

\subsection{PSS tools development}

The PSS tools include SPL Meter and PSS Server. SPL Meter (which can be downloaded at http://www.citi-sense.cn/download) is a soundscape data investigation and analysis software package that can be installed on both Android and iOS operating systems. PSS Server runs on a cloud server and can analyze and visualize soundscape data online from around the world (http://pss.citi-sense.cn).

Fig.1 shows the logical architecture of SPL Meter contains four main components, including SPL calculation, location and sound source identification, demographic information and time collection, and results storage and sharing.

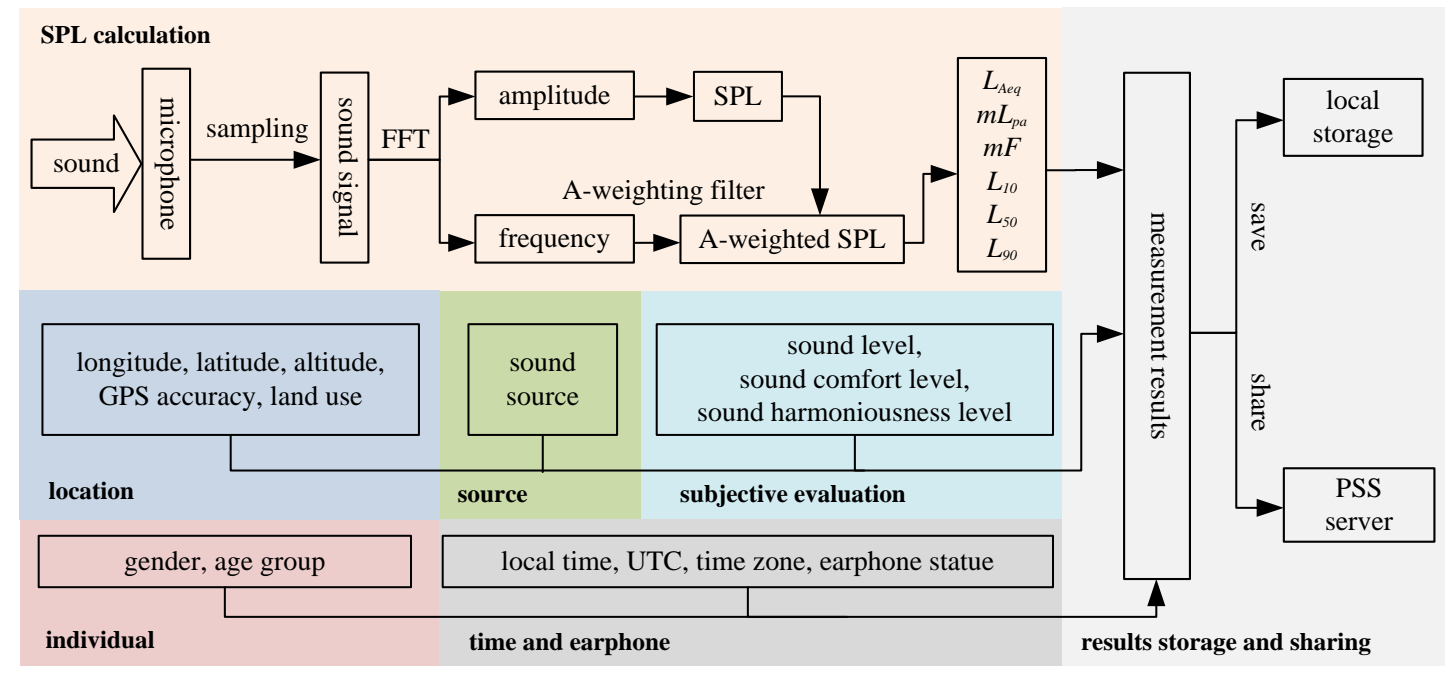

Fig. 1. Logical architecture for SPL Meter 

human ear senses tones resulting from sound oscillation at frequencies between 20 and 20,000 Hertz $(\mathrm{Hz})$, and the most sensitive frequencies span the range of 2,000 $\mathrm{Hz}$ to $5,000 \mathrm{~Hz}$. SPL Meter receives 16-bit PCM (pulse-code modulation is a digital representation of an analogue signal) at a speed of $44,100 \mathrm{~Hz}$ from its microphone. SPL Meter extracts the amplitude and frequency from the sampled signal using the Fast Fourier Transformation (FFT). For the purpose of this application, the calculation method of FFT comes from the ddf.minim.analysis package and the block size was set as 2,048 in FFT. The human ear does not respond to these frequencies equally well and is less sensitive to extreme high and low frequencies; therefore, an A-weighted SPL, which is modified by the A-weighting filter, is commonly used in noise dose measurement at work. The A-weighted equivalent continuous sound level $\left(L_{\text {Aeq }}\right)$, maximum sound level $\left(m L_{p a}\right)$ and its corresponding frequency $(m F)$, the sound level exceeded for $10 \%$ of the time of the measurement duration $\left(L_{10}\right)$, the sound level exceeded for $50 \%$ of the time of the measurement duration $\left(L_{50}\right)$, and the sound level exceeded for $90 \%$ of the time of the measurement duration $\left(L_{90}\right)$ can be calculated using A-weighted SPL. The calculation results are shown on the main screen of the SPL Meter by numeric representation or as a graph.

Location and sound source identification. Differences in land use and sound sources can affect the perception of the soundscape (Kang, 2007). The information for land use and sound sources can be identified by the participants using a list in the evaluation interface of the SPL to PSS Server each time it starts. Each item of the land use and sound sources has a unique code. The lists are updated if new items (sound source or land use information) are added to the lists in PSS server. The location coordinates are collected using the mobile phone's high-accuracy location service (GPS, WLAN, or mobile networks).

100 Soundscape evaluation. The subjective evaluation of sound levels, sound comfort levels, and sound harmoniousness levels, which are widely used in soundscape evaluation (Aspuru et 
103 linear scales that were standardized in noise surveys (Fields, et al., 2001). The level of

104 harmonization between aural and visual perception has been defined as sound

105 harmoniousness level in this study. Information related to the gender and age of the

106 participants can also be collected if the user is willing to supply them. The local time, time

107 zone, and UTC are obtained when SPL Meter is used to measure and evaluate the soundscape.

108 The state of the earphone is necessary to judge whether the internal or external microphone

109 is used. Other hardware and software variations might exist if an external microphone of

110 unknown properties is used, but we can expect that most mobile phones' internal microphone

111 typically has a sensitivity of $-50 \mathrm{~dB}$. The notification of the PSS server can be shown on the

112 top of the main interface, which is useful for PSS project maintenance. Measurements can be

113 stored in the mobile phones or they can be shared with the PSS server.

114 Participatory results visualization. Real-time measurements are submitted by the

115 participants and analyzed on PSS server, and the subsequent analytical results are illustrated

116 on the website using maps, pie charts, and histograms. Information on the interface includes

117 the number of total participants and records; the proportion of place types, sound sources, age,

118 and gender; and evaluation of sound level, sound comfort, and sound harmoniousness. The

119 media of SPL, maxSPL, equivalent SPL, and frequency are also presented on the web page,

120 as illustrated in Fig. 2.

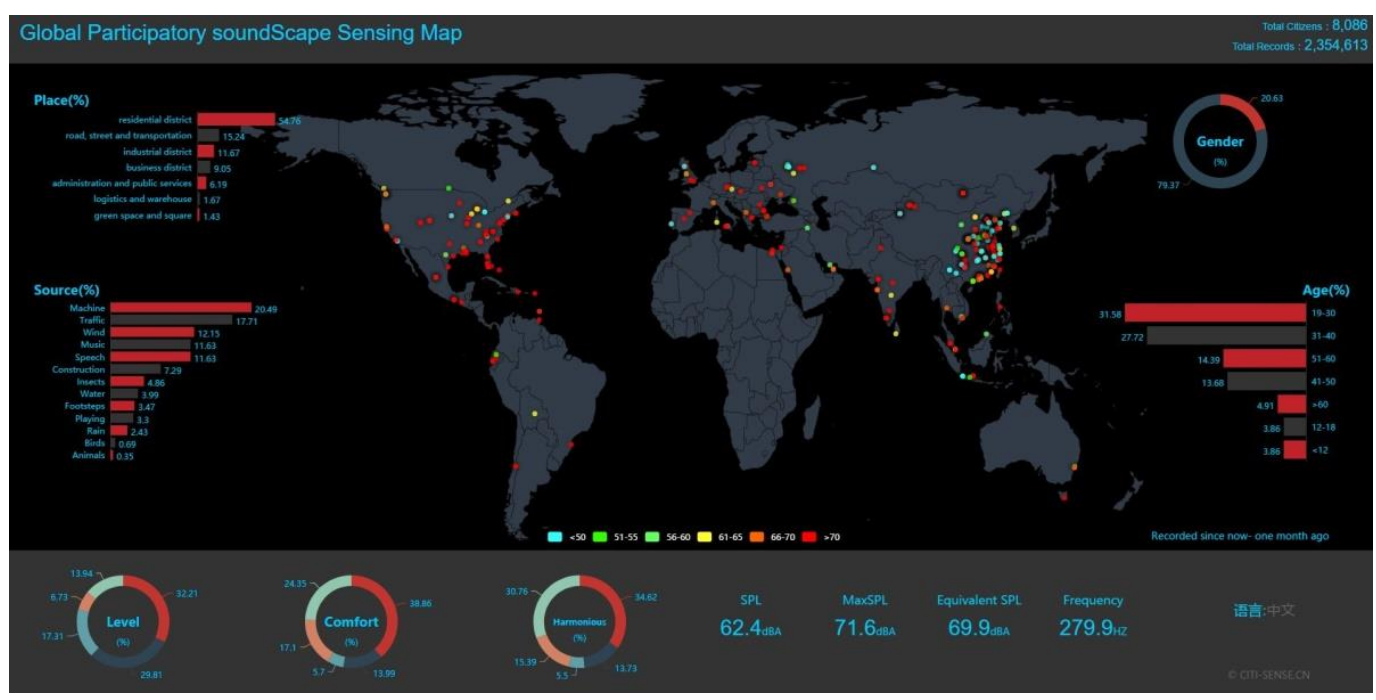

Fig. 2. PSS online analysis and visualization website 


\subsection{SPL data calibration}

124 The sensitivity of the mobile phone microphone is much lower than that of a purpose-built sound meter (e.g., the sensitivity of HS5633T is $-31.7 \mathrm{~dB}$ ). Microphones from different mobile phone companies have different sensitivities and should be calibrated before measuring the SPL. Kardous and Shaw (2014) used pink noise with a $20 \mathrm{~Hz}$ to 20,000 Hz frequency range, at levels from $65 \mathrm{~dB}$ to $95 \mathrm{~dB}$, and Aumond et al. (2017) used white noise from $35 \mathrm{dBA}$ to $100 \mathrm{dBA}$ to calibrate their mobile phones. In this study, firstly, four different model types of mobile phones equipped with SPL Meter and a sound pressure meter (SPM) (HS5633T/Heng Sheng Electronics) that meet the National Verification Regulation of Sound Level Meters (JJG188-2002) were put together in the same sound field. The distance between

133 the phones' microphone and the speaker was 1 meter. Secondly, we generated different

134 frequency noise with $20 \mathrm{~Hz}$ to $20,000 \mathrm{~Hz}$ noise to test our phones and SPM at the same time, and calculated the correlation parameters with SPM at levels from $35 \mathrm{dBA}$ to $90 \mathrm{dBA}$ using the linear regression method. Finally, these calibrated mobile phones were used outdoors to measure the equivalent SPL three times, with each measurement lasting for 20 minutes. Additionally, a 94 dBA consistent sound source device (HS6020/Heng Sheng Electronics)

139 was used before and after each measurement to control the error of SPM (not exceeding 0.5 $140 \mathrm{dBA})$.

\section{$141 \quad$ 2.3. Data quality analysis}

142 After more than a year of operation (from March $1^{\text {st }}, 2016$ to August $31^{\text {st }}, 2017$ ), we 143 obtained the PSS data temporal variation, spatial distribution and accuracy of GPS, and 144 analyzed the participants' age and gender impacts on the data quality, including the ratio of 145 shared measurements, length of measurement time, and integrity of measurement records.

146 The records integrity describes the proportion of each soundscape related indictor recorded:

147 for example, if there are 50 GPS records in 100 measurement activities, the integrity of GPS 148 indicators is 50\%. In addition, we analyzed the sound comfort level relationships with each 149 class of land use, sound sources, subjective evaluation sound level, sound harmoniousness, 150 gender, and age. 


\subsection{SPL data validation}

153 During the study period, we received observations from 470 model types belonging to 45

154 mobile phone manufacturers. Certain models that we have were calibrated, while others can

155 be calibrated in a similar manner. Fig. 3 shows that these mobile phones have good

156 correlation with SPM. Table 1 shows the average error between each of the mobile phones

157 and SPM is $0.3 \mathrm{dBA}$ (HTC Desire), $0.8 \mathrm{dBA}$ (HTC Wildfire), $1.2 \mathrm{dBA}$ (HTC Incredible), and

$1580.7 \mathrm{dBA}$ (SAMSUNG I9000), meaning that the calibrated mobile phones are suitable for

159 measuring SPL.

160

161

162

163

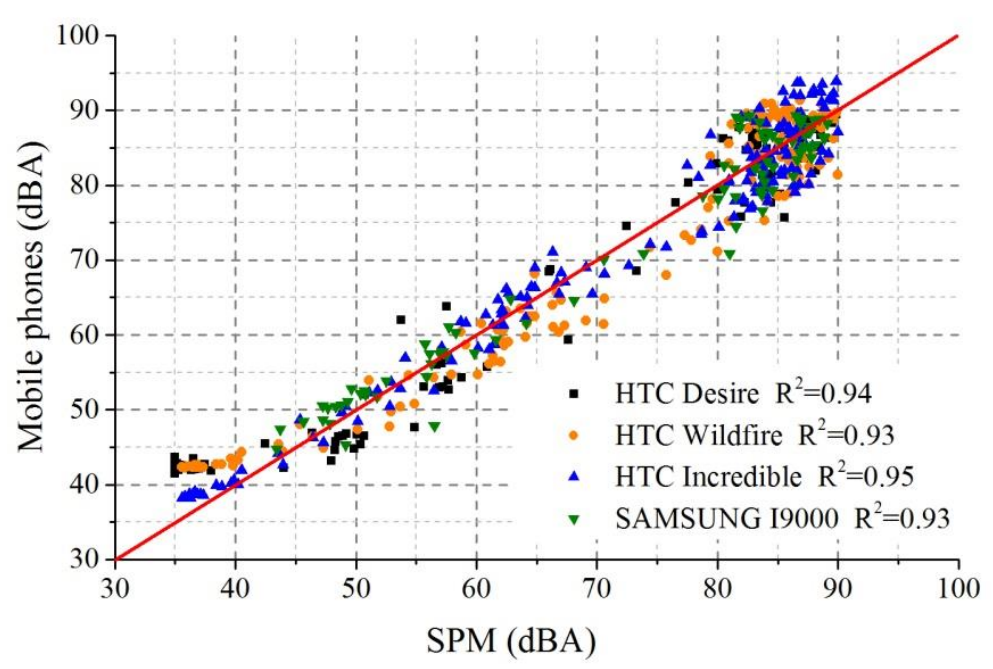

Fig. 3. Different mobile phones compared with SPM

Table 1

The $L_{A e q}$ values of SPM and mobile phones in the same outdoor environment (dBA)

\begin{tabular}{lrccccc}
\hline ID & SPM & $\begin{array}{c}\text { error of SPM } \\
\text { (before, after) }\end{array}$ & $\begin{array}{c}\text { HTC Desire } \\
\text { (error) }\end{array}$ & $\begin{array}{c}\text { HTC } \\
\text { Wildfire } \\
\text { (error) }\end{array}$ & $\begin{array}{c}\text { HTC } \\
\text { Incredible } \\
\text { (error) }\end{array}$ & $\begin{array}{c}\text { SAMSUNG } \\
\text { I9000 } \\
\text { (error) }\end{array}$ \\
\hline 1 & 49.2 & $0.4(94.3,93.9)$ & $49.5(0.3)$ & $49.8(0.6)$ & $50.4(1.2)$ & $49.9(0.7)$ \\
2 & 49.0 & $0.1(94.2,94.3)$ & $49.2(0.2)$ & $49.9(0.9)$ & $50.2(1.2)$ & $49.5(0.5)$ \\
3 & 49.1 & $0.4(94.2,94.6)$ & $49.4(0.3)$ & $50.0(0.9)$ & $50.4(1.3)$ & $50.1(1.0)$ \\
\hline
\end{tabular}


165 The number of participants has continuously increased since the release of SPL Meter on 166 the app market (e.g., Google Play, iTunes, Baidu, QQ, anzhi, etc.) in March 2016. Over

16711,326 downloads were recorded at the end of August 2017, and approximately 5,601

168 participants shared 25,471 measurement records. Wi-Fi is the main channel for data sharing

169 (Android: $60.78 \%$, IOS: 64.22\%). Fig. 4 shows that measurements were mainly concentrated

170 from 9:00 am to 11:00 pm, which is closely related to the temporal pattern of the human

171 work-rest schedule. The number of women was less than the number of men (women: $9.8 \%$,

172 men: 90.2\%), which may explain why the daily variation of women is uneven.

173 The measurement sites gradually spread around the world at the end of August 2017, as

174 indicated in Fig. 5. Numerous populations, ubiquitous networks, and plentiful numbers of

175 mobile application markets make the measurement sites in China and USA much more

176 numerous than in other locations.

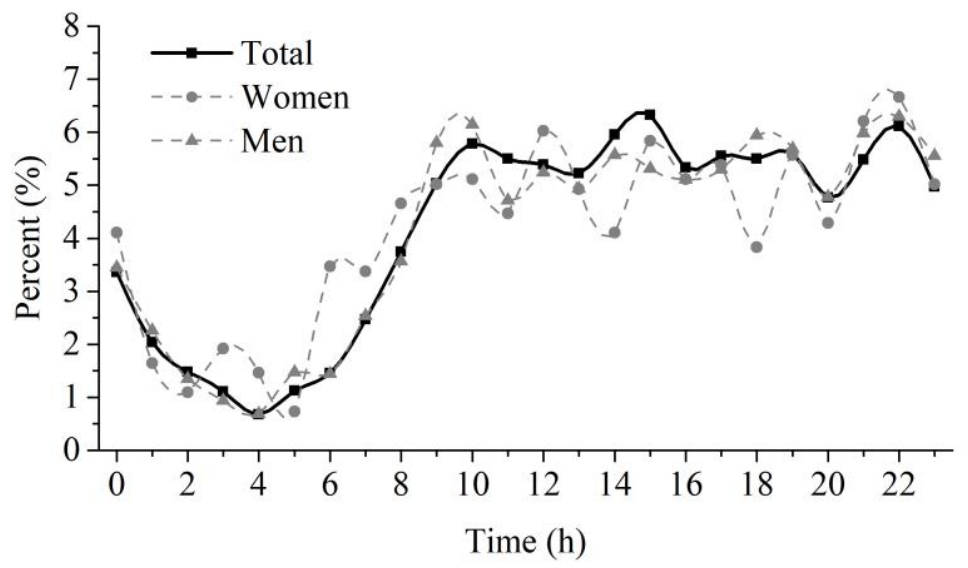

Fig. 4. Daily variation of measured activities 


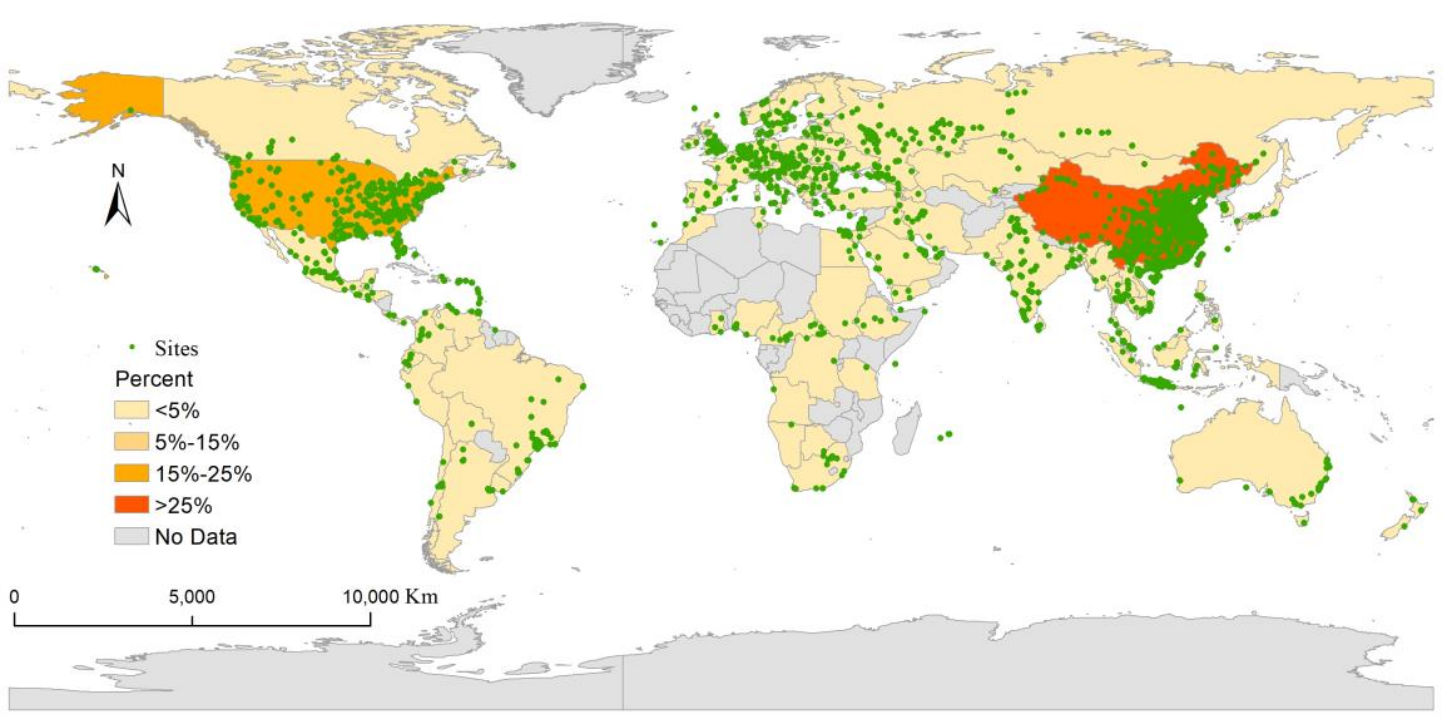

Fig. 5. Map of measured sites and percentages in each country

\section{$181 \quad 3.3$. Data quality impacted by gender and age}

182 A complete measurement record includes information on $L_{A e q}, m L_{p a}, m F, L_{10}, L_{50}, L_{90}$, land use, GPS, gender, age, sound sources, and subjective sound evaluation level (level, comfort, and harmoniousness). The first six physical indicators described the sound and are not impacted by the participants' demographic biases. The subjective soundscape evaluation, sound sources, and class of land use identification, which require knowledge other than gender and age, are uneven in the differences among participants' demographic biases. Fig. 6 shows the record integrity for participants under 12 years old was much lower than that of other age groups. Women show better performance in data integrity (completing the recording)

190 than men. The accuracy of GPS is easily affected by the surroundings, but most distances

$191(81.5 \%)$ are less than 50 meters.

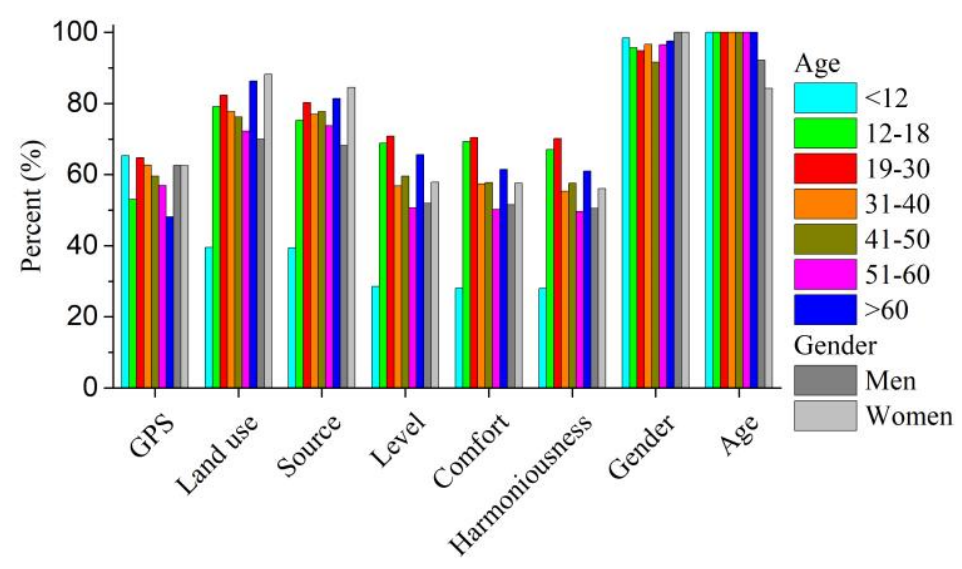


194

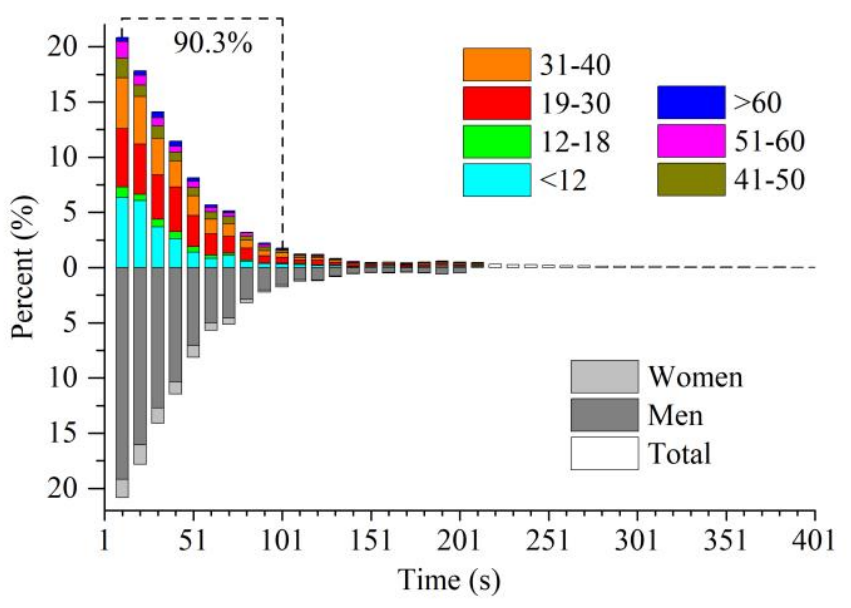

Fig. 7. Gender and age impacts on measured time

The longer the measurement time, the more meaningful the results are. Fig. 7 shows the length of each use of SPL Meter time was mainly (90.3\%) concentrated in the range of 10 seconds to 101 seconds and half of the measurement activities (50.7\%) were initiated by participants 19 to 40 years of age. The ratio of participants whose ages are under 12 years old decreased most rapidly with increased measurement time as shown in Fig. 7, which suggests that these participants have more difficulty in supplying richer records than the other age groups. The percentage of men was significantly higher than women in the different measurement time (The $\mathrm{p}$-value is 0.006 in $\mathrm{t}-$ Test at $\mathrm{p}<0.01$ level).

\subsection{Sound comfort evaluation}

When the sound comfort level is shifted from very uncomfortable to very comfortable, Fig. 8 shows the proportion of natural sources continuously increases (from $15.23 \%$ to $41.02 \%$ ) and the proportion of human-made sources continuously decreases (from $68.42 \%$ to $36.21 \%$ ), but the proportion of music (which is one of the human-made source sounds) increases. The proportion of human activity sources increases from a very uncomfortable level to a comfortable level but decreases at the very comfortable level. Water sounds are the most likely to make people feel more sound comfortable as compared to other natural source sounds. In addition, machine sound is the most unwelcome sound. 


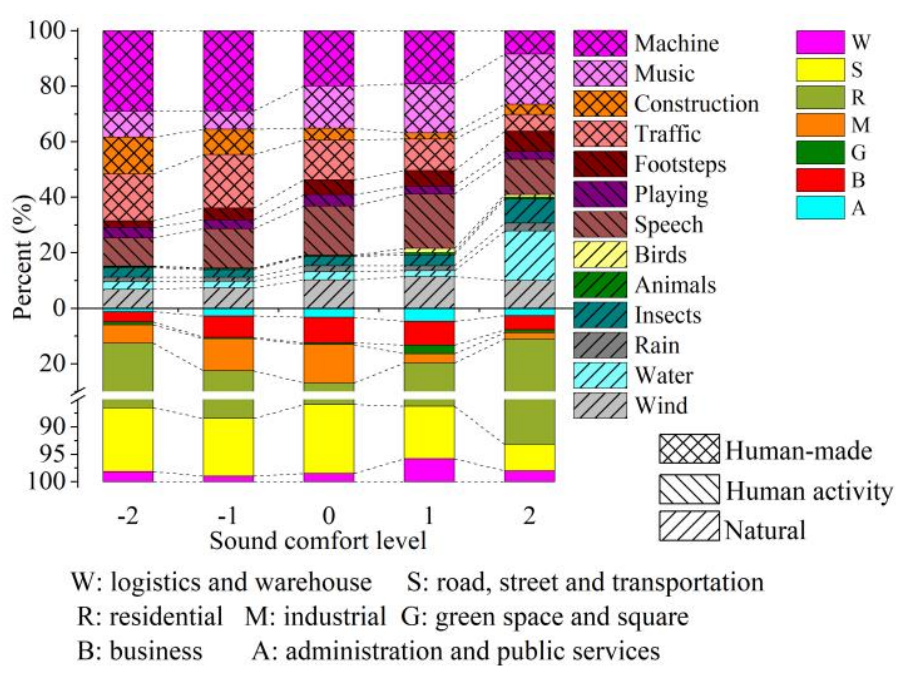

214 Fig. 8. Percentage of sound sources and land uses at different sound comfort levels

215 Most of the measurement activities were conducted in a residential area (R). The categories

216 of business area (B), industrial area (M), and road, street, and transportation area (S) have

217 lower proportions at the highest sound comfort level.

218 Based on the results, we find that increasing the proportion of natural source sounds and 219 more reasonable land use configurations that reduce the proportion of human-made source 220 sounds can be expected to enhance the sound comfort level. However, increasing human 221 activities source sound does not decrease sound comfort.

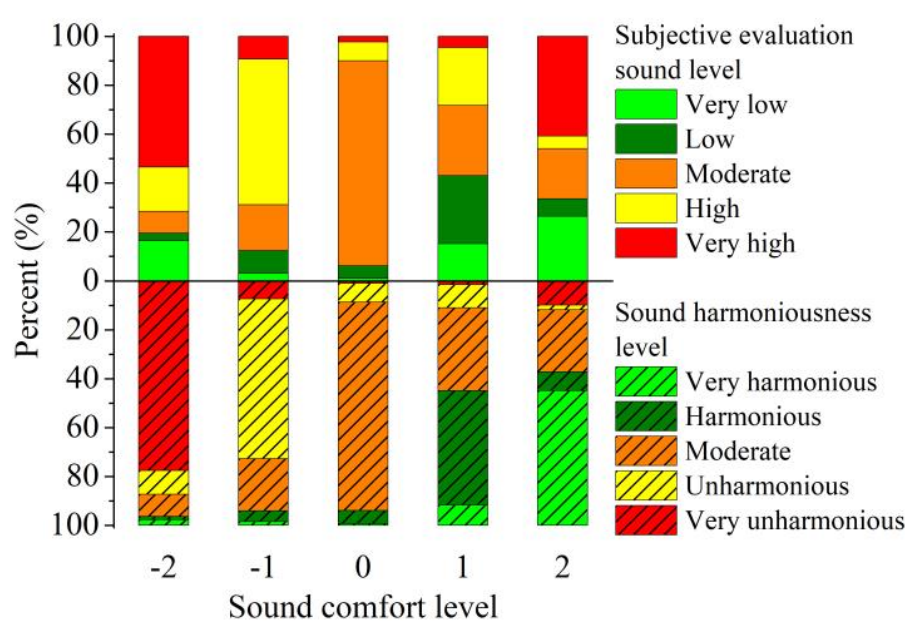

223 Fig. 9. Percentage of subjective evaluation sound level and sound harmoniousness at different sound comfort levels

225 When the sound comfort level is shifted from very uncomfortable to very comfortable, Fig. 2269 shows the sound harmoniousness level is also enhanced, whereas the subjective evaluation 
sound level does not decrease, which means that the sound harmoniousness levels are more

228 valuable than the subjective evaluation of sound level.

229 In addition, we find that, when the sound comfort level is shifted from very comfortable to

230 very uncomfortable, the ratio of participants that are women and older than 60 years

231 continuously increases. The women's ratio increased by a factor of five (from $4.22 \%$ to

$23222.54 \%$ ), and the ratio for the age group older than 60 years increased by $7 \%$ (from $2.21 \%$ to

$2339.21 \%$ ). The results show that elderly people and women may be more easily negatively

234 affected by environmental noise.

\section{4. Conclusions}

236 PSS assigns the task of standardized data collection and calculation to citizens around the 237 world with the aid of SPL Meter and mobile networks. Citizens can be involved at any time 238 and any location with their smart devices, and a long-term research network can be easily and 239 quickly formed with more participants, which is highly useful for improving data collection 240 efficiency and accumulating large data sets for soundscape research, design, and planning.

241 The PSS data temporal-spatial distribution is closely related to the temporal pattern of the 242 human work-rest schedule, population density, and level of cyber-infrastructure. The data 243 quality primarily depends on the knowledge of the individuals or communities and the 244 capabilities of their devices, which is different from that of data from questionnaires guided 245 by interviewers in situ. Rich and specific classification of sound sources and land use is 246 expected to supply more valuable data, but it might decrease the user experience and lead to 247 complicated operation or even abandonment of the tools. As a result, the question of how to 248 help citizens from different cultures and knowledge levels to understand the terminology and 249 to simplify and standardize the operation of software and devices will be a great challenge in 250 the future.

251 Because the sound comfort level has a close relationship with demographic biases and land 252 use, sound pressure level control is an important method used to improve the sound comfort 253 level, whereas other methods, including enhancing the ratio of natural source sounds (water, 254 insects, etc.), more reasonable land use configurations to reduce the ratio of human-made 
255 source sounds, and enhancing the sound harmoniousness level, are expected to be helpful in 256 improving the sound comfort level. 


\section{References}

Aletta, F., Kang, J., \& Axelsson, Ö. (2016). Soundscape descriptors and a conceptual framework for developing predictive soundscape models. Landscape and Urban Planning, 149, 65-74. https://doi.org/10.1016/j.landurbplan.2016.02.001

Aspuru, I., García, I., Herranz, K., \& Santander, A. (2016). CITI-SENSE: methods and tools for empowering citizens to observe acoustic comfort in outdoor public spaces. Noise Mapping, 3, 37-48. http://dx.doi.org/10.1515/noise-2016-0003

Aumond, P., Lavandier, C., Ribeiro, C., Boix, E.G., Kambona, K., D’Hondt, E., \& Delaitre, P. (2017). A study of the accuracy of mobile technology for measuring urban noise pollution in large scale participatory sensing campaigns. Applied Acoustics, 117(Part B), 219-226. https://doi.org/10.1016/j.apacoust.2016.07.011

Becker, M., Caminiti, S., Fiorella, D., Francis, L., Gravino, P., Haklay, M., Hotho, A., Loreto, V., Mueller, J., Ricchiuti, F., Servedio, V.D.P., Sirbu, A., \& Tira, F. (2013). Awareness and Learning in Participatory Noise Sensing. PLoS ONE, 8(12): e81638. https://doi.org/10.1371/journal.pone.0081638

Brown, A.L. (2012). A review of progress in soundscapes and an approach to soundscape planning. International Journal of Acoustics and Vibration, 17(2), 73-81. http://hdl.handle.net/10072/50262

Burke, J.A., Estrin, D., Hansen, M., Parker, A., Ramanathan, N., Reddy, S., \& Srivastava, M.B. (2006). Participatory sensing. http://escholarship.org/uc/item/19h777qd/ Accessed 14 March 2017

Chung, A., To, W.M., \& Schulte-Fortkamp, B. (2016). Next generation soundscape design using virtual reality technologies. The Journal of the Acoustical Society of America, 140(4), 3041-3041. http://dx.doi.org/10.1121/1.4969442

Cordeiro, J., Barbosa, Á., \& Afonso, B. (2013). Soundscape-Sensing in Social Networks. AIA-DAGA 2013 Proceedings of Conference on Acoustics. Merano, EAA Euroregio. http://www.abarbosa.org/docs/Barbosa_AIADAGA-2013.pdf 
Craig, A., Moore, D., \& Knox, D. (2017). Experience sampling: Assessing urban soundscapes using in-situ participatory methods. Applied Acoustics, 117(Part B), 227-235. http://dx.doi.org/10.1016/j.apacoust.2016.05.026

Drosatos, G., Efraimidis, P.S., Athanasiadis, I.N., Stevens, M., \& Hondt, E.D. (2014). Privacy-preserving computation of participatory noise maps in the cloud. Journal of Systems and Software, 92,170-183. https://doi.org/10.1016/j.jss.2014.01.035

Estrin, D., Chandy, K.M., Young, R.M., Smarr, L., Odlyzko, A., Clark, D., Reding, V., Ishida, T., Sharma, S., Cerf, V.G., Hölzle, U., Barroso, L.A., Mulligan, G., Hooke, A., \& Elliott, C. (2010). Participatory sensing: applications and architecture. IEEE Internet Computing,14,12-42. https://doi.org/10.1109/MIC.2010.12

Fields, J.M., DeJong, R.G., Gjestland, T., Flindell, I.H., Job, R.F.S., Kurra, S., Lercher, P., Vallet, M., Yano, T., Guski, R., Felscher, S.U., \& Schumer, R. (2001). Standardized general-purpose noise reaction questions for community noise surveys: research and a recommendation. Journal of Sound and Vibration, 242(4), 641-679. https://doi.org/10.1006/jsvi.2000.3384

He, M., \& Pang, H. (2016). A review of soundscape research history and progress. Landscape Architecture, 88-97. https://doi.org/10.14085/j.fjyl.2016.05.0088.10

Hedfors, P. (2013). Mobile app for the characterization of soundscapes. http://www.slu.se/en/departments/urban-rural-development/research/landscape-architect ure/projects/soundscapes/ Accessed 14 March 2017

Hong, J.Y., \& Jeon, J.Y. (2017). Exploring spatial relationships among soundscape variables in urban areas: A spatial statistical modelling approach. Landscape and Urban Planning, 157, 352-364. http://dx.doi.org/10.1016/j.landurbplan.2016.08.006

International Organization for Standardization. (2014). ISO 12913-1:2014 Acoustics Soundscape - Part 1: Definition and Conceptual Framework. https://www.iso.org/obp/ui/\#iso:std:iso:12913:-1:ed-1:v1:en/ Accessed 14 March 2017 
Jeon, J.Y., \& Hong, J.Y. (2015). Classification of urban park soundscapes through perceptions of the acoustical environments. Landscape and Urban Planning, 141, 100-111. http://dx.doi.org/10.1016/j.landurbplan.2015.05.005

Kang, J. (2007). Urban Sound Environment ( $1^{\text {st }}$ ed.). New York: Taylor \& Francis

Kang, J. (2014). Soundscape: Current progress and future development. New Architecture, $4-7$.

Kardous, C.A., \& Shaw, P.B. (2014). Evaluation of smartphone sound measurement applications. The Journal of the Acoustical Society of America, 135, EL186, https://doi.org/10.1121/1.4865269

Liu, J., Kang, J., Luo, T., Behm, H., \& Coppack, T. (2013). Spatiotemporal variability of soundscapes in a multiple functional urban area. Landscape and Urban Planning, 115, 1-9. http://dx.doi.org/10.1016/j.landurbplan.2013.03.008

Liu, J., Kang, J., Behm, H., \& Luo, T. (2014). Effects of landscape on soundscape perception: Soundwalks in city parks. Landscape and Urban Planning, 123, 30-40. http://dx.doi.org/10.1016/j.landurbplan.2013.12.003

Smith, S.W. (1999). The scientist and engineer's guide to digital signal processing ( $\left.2^{\text {nd }} e d.\right)$. California: California Technical Pub.

Yang, W., \& Kang, J. (2005). Acoustic comfort evaluation in urban open public spaces. Applied Acoustics, 66(2), 211-229. http://dx.doi.org/10.1016/j.apacoust.2004.07.01

Yelmi, P., Kuscu, H., \& Yantac, A.E. (2016). Towards a sustainable crowdsourced sound heritage archive by public participation: the soundsslike project. The 9th Nordic Conference on Human-Computer Interaction, Sweden.1-9. https://doi.org/10.1145/2971485.2971492

Zhang, D., Zhang, M., Liu, D., \& Kang, J. (2016). Soundscape evaluation in Han Chinese Buddhist temples. Applied Acoustics, 111, 188-197. http://dx.doi.org/10.1016/j.apacoust.2016.04.020 